Article

\title{
Genetic Mapping of a Major Resistance Gene to Pea Aphid (Acyrthosipon pisum) in the Model Legume Medicago truncatula
}

\author{
Lars G. Kamphuis ${ }^{1,2}$, , Su-Min Guo ${ }^{1,3}$, Ling-Ling Gao ${ }^{1}$ and Karam B. Singh ${ }^{1,2}$ \\ 1 Commenwealth Scientific and Industrial Research Organisation, Agriculture and Food, \\ 147 Underwood Avenue, Floreat, WA 6014, Australia; sg877@cornell.edu (S.-M.G.); \\ lingling.gao@csiro.au (L.-L.G.); karam.singh@csiro.au (K.B.S.) \\ 2 University of Western Australia Insititute of Agriculture, 35 Stirling Highway, Crawley, WA 6009, Australia \\ 3 Boyce Thompson Institute for Plant Research, Ithaca, NY 14853, USA \\ * Correspondence: lars.kamphuis@csiro.au; Tel.: +61-8-9333-6320
}

Academic Editor: Massimo Maffei

Received: 21 June 2016; Accepted: 22 July 2016; Published: 29 July 2016

\begin{abstract}
Resistance to the Australian pea aphid (PA; Acyrthosiphon pisum) biotype in cultivar Jester of the model legume Medicago truncatula is mediated by a single dominant gene and is phloem-mediated. The genetic map position for this resistance gene, APR (Acyrthosiphon pisum resistance), is provided and shows that APR maps 39 centiMorgans (cM) distal of the $A$. kondoi resistance (AKR) locus, which mediates resistance to a closely related species of the same genus bluegreen aphid (A. kondoi). The APR region on chromosome 3 is dense in classical nucleotide binding site leucine-rich repeats (NLRs) and overlaps with the region harbouring the RAP1 gene which confers resistance to a European PA biotype in the accession Jemalong A17. Further screening of a core collection of M. truncatula accessions identified seven lines with strong resistance to PA. Allelism experiments showed that the single dominant resistance to PA in M. truncatula accessions SA10481 and SA1516 are allelic to SA10733, the donor of the APR locus in cultivar Jester. While it remains unclear whether there are multiple PA resistance genes in an R-gene cluster or the resistance loci identified in the other M. truncatula accessions are allelic to APR, the introgression of APR into current $M$. truncatula cultivars will provide more durable resistance to $P A$.
\end{abstract}

Keywords: barrel medic; legumes; insect resistance; resistance gene

\section{Introduction}

Sap-sucking insects such as aphids, psyllids, scales and whiteflies cause significant damage in agricultural crops throughout the world. Damage is caused by direct feeding from the phloem sap as well as vectoring viruses, with aphids transmitting over $50 \%$ of all plant viruses [1]. Sap-sucking insects have a close association with their host and feed from a single cell type, the phloem sieve element. Sap-sucking insects have developed the ability to disguise their presence and/or suppress plant defences, ultimately leading to the establishment of a successful feeding site [2,3]. In recent years an increased research focus on studying plant—sap-sucking insect interactions has occurred, resulting in the identification of several sap-sucking insect resistance loci $[4,5]$ and an improved understanding of the molecular mechanisms of basal defense as well as gene mediated resistance to sap-sucking insects is emerging [5].

The evolutionary origins of recognition of attackers of plants mainly stems from studies involving plant pathogens rather than insects and is better known as the plants innate immune system [6]. Recognition of an attacker often occurs through resistance $(R)$ gene products which recognize specific 
attacker-derived product(s) and upon recognition mount a defence response. While these $R$-genes mediate resistance to a variety of different pathogens and pests, their architecture is highly similar and includes one of the following conserved motifs: Nucleotide binding site, leucine-rich repeat (NLRs) or serine/threonine protein kinase domains. This would imply that basic modes of recognition and subsequent signalling pathways that trigger the defence response have been retained through plant evolution and diversification $[7,8]$.

An important advance in understanding $R$-gene mediated resistance to sap-sucking insects came from the discovery of the major dominant resistance gene Mi1.2, which confers resistance to three sap-sucking insects, being potato aphid (Macrosiphum euphorbiae), whiteflies (Bemisia tabaci) biotypes B and Q and psyllids (Bactericerca cockerelli) as well as three species of root-knot nematodes (Meloidogyne spp.) [9-11]. The second major R-gene identified and cloned was the Vat gene conferring resistance to cotton-melon aphid (Aphis gossypii) [12]. Mi1.2 and Vat belong to the largest class of $R$-genes encoding proteins with NLR motifs of the subclass with coiled-coiled (CC) motifs. The silencing of the Resistance Gene Candidate 2 (RGC2) cluster of NLR encoding genes in lettuce (Lactuca sativa) led to the loss of resistance to the lettuce root aphid (Phemphigus bursarius) [13]. In the model legume Medicago truncatula, single dominant resistance genes to other aphid species including bluegreen aphid (BGA; Acyrthosiphon kondoi), spotted alfalfa aphid (Therioaphis trifolii) and pea aphid (PA; Acyrthosiphon pisum) map to regions dense in these NLR encoding genes [14-17]. For both Mi1.2 and Vat as well as the single dominant resistance genes identified in M. truncatula resistance to aphids is exerted in the phloem, which shows that plants are able to utilize their innate immune systems to defend against parasitism of the phloem.

Over the last decade M. truncatula has emerged as an excellent model plant to study plant insect interactions [5,18], with major dominant resistance genes identified to bluegreen aphid [14], spotted alfalfa aphid [15] and pea aphid [17,19]. Furthermore, quantitative trait loci (QTLs) controlling different aspects of aphid resistance including antibiosis, antixenosis and tolerance to BGA, PA, spotted alfalfa aphid and cowpea aphid have been identified [20-22]. Resistance to BGA, PA and spotted alfalfa aphid has been introgressed into the M. truncatula variety Jemalong (A17) through recurrent backcrosses to create a new aphid-resistant cultivar Jester $[19,23]$. Resistance to these three aphid species in Jester has been dissected over the last decade and it was shown that in all cases it involves antibiosis and antixenosis, with resistance exerted at the phloem [14,15,24].

Resistance in M. truncatula to PA was of particular interest as PA has been chosen by the international aphid genome consortium (IAGC) as the model aphid and there is a reference genome sequence [25] and other genomic resources available [26] as well as a number of distinct PA biotypes [27]. In the case of the Medicago-PA interaction in Jester, it was unclear whether resistance to BGA and PA was conferred by the same single dominant resistance gene, AKR (Acyrthosiphon kondoi resistance). In 2009, Guo et al. demonstrated that resistance to the Australian PA biotype was introgressed into the Jester background from a different donor than the resistance to BGA, thus there were two distinct resistance genes for the Australian PA biotype and BGA, where the resistance locus to the Australian PA biotype was termed APR for Acyrthosiphon pisum resistance [19]. In M. truncatula resistance to an European pea aphid biotype (PS01) is distinct from resistance to the Australian biotype. Resistance to the European biotype was identified in M. truncatula accession A17 which is moderately resistant to the Australian biotype [17]. Like APR mediated resistance RAP1 resistance is also exerted through the phloem. The genetic map position of $R A P 1$ is on linkage group 3 in a region harbouring both serine-threonine kinase and NLR proteins. RAP1 mediated resistance causes $100 \%$ mortality to the European clone PSO1 and is therefore different from APR mediated resistance since the antibiotic effect of $A P R$ on the Australian PA biotype shows no mortality, but rather a reduced reproductive rate $[17,24]$.

Here we present a genetic map position for the APR locus and demonstrate that APR and RAP1 map to the same region on chromosome 3. We also report on a screen of additional M. truncatula germplasm for PA resistance and elaborate on the hypotheses that APR and RAP1 are two distinct genes tightly linked to one another in an $R$-gene cluster, or are alternative alleles of the same locus. 


\section{Results}

\subsection{Resistance to Pea Aphid in the Cultivar Jester Is Controlled by a Single Dominant Gene}

Previous mapping data suggested that PA resistance in Jester was linked to that of bluegreen aphid resistance mediated by the $A K R$ locus on chromosome 3 [24]. To identify the genetic location of the APR locus, two genetic mapping populations were developed between Jester and A20, a wide cross as well as Jester and A17, a narrow cross. Molecular markers developed by the M. truncatula community [28-30], were screened for polymorphisms between the parents for each population (Table S1). A total of $129 \mathrm{~F}_{2}$ individuals were genotyped with 15 molecular markers polymorphic between Jester and A20. This resulted in the construction of a genetic linkage map for chromosome 3 spanning 100.9 centiMorgans (cM) with an average interval size of $7.2 \mathrm{cM}$. Seed was collected for these 129 individuals and their $\mathrm{F}_{3}$ offspring ( $n=12$ per $\mathrm{F}_{3}$ family) was infested with PA to determine their PA resistance response and thus the $\mathrm{F}_{2}$ alleles for the APR locus. This determined that the PA resistance locus $A P R$ is located between markers h2_39a22a and h2_180m21a spanning a 12.1 cM interval (Figure 1).

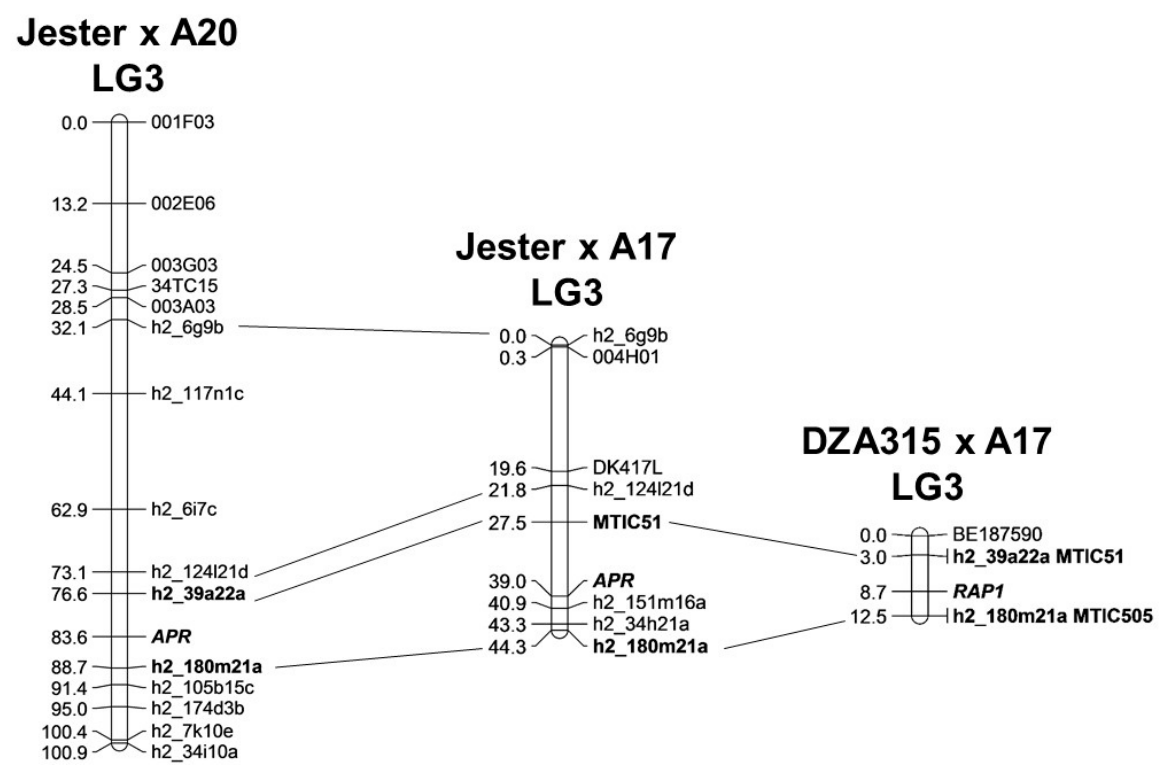

Figure 1. Genetic map position of the APR (Acyrthosiphon pisum resistance) locus conferring resistance to the Australian pea aphid biotype, covers the same region of interest as the region of interest for $R A P 1$ conferring resistance to a European PA biotype in the genetic background A17.

Jester and A17 are 89\% identical in their genome organisation [19] with Jester mainly having a large insertion from different donors on chromosome 3. Therefore, the chance to identify recombinants in the APR region of interest from a cross derived between Jester and A17 is higher than that from a cross derived between Jester and A20; thus, $384 \mathrm{~F}_{2}$ individuals of the narrow cross derived between Jester and A17 were genotyped with eight polymorphic markers near the region of $A P R$ to identify individuals with recombination events around the APR locus. This identified a total of 26 individuals with recombination events in the $A P R$ region of interest and their $\mathrm{F}_{3}$ progeny ( $n=12$ per $\mathrm{F}_{3}$ family) were infested with PA to determine their resistance status. As shown in Figure 1 the region of interest for the APR locus in the Jester $\times$ A17 cross spans 13.4 cM between markers MTIC51 and h2_151m16a. This region spans a physical distance of $3972.4 \mathrm{~Kb}$ in the M. truncatula $\mathrm{v} 4.0$ genome assembly of accession A17, which harbours a cluster of classical nucleotide-binding site leucine-rich repeats (NLR) resistance genes, including the RAP1 resistance gene to the European PA clone LS01 [17], but not the region where the bluegreen aphid resistance gene $A K R$ has been mapped [14]. 


\subsection{Screening of M. truncatula Accessions for Additional Sources of PA Resistance}

With both $A P R$ and RAP1 located in an NLR cluster on chromosome 3, we wanted to determine whether additional major PA resistance genes to the Australian PA biotype exist besides APR and perhaps with a more striking lethal resistance as conferred by $R A P 1$ to the European PA biotype LS01. Therefore, additional lines of M. truncatula were screened for aphid performance and plant damage. Thirty-five accessions of the South Australian Research and Development Institute (SARDI) M. truncatula core collection, which represent the major clades in the phylogenetic tree of the SARDI core accessions [31] were selected to evaluate PA resistance performance. These included accessions A20, Cyprus and Borung, previously identified as being highly susceptible to PA, A17 which is moderately resistant, as well as Jester and Caliph which are highly resistant to PA [32]. Plant damage and aphid populations were monitored over a 28-day period. One of the typical aphid infestation phenotypes in M. truncatula following infestation with PA is necrotic flecks on local leaves $[17,24]$; however this was only observed in M. truncatula accessions Jester and A17. No lethal resistance to PA was observed and all accessions showed varying degrees of stunting and wilting, with damage symptoms appearing as yellowing patches or leaf chlorosis surrounding the aphid infestation sites within 9 days after infestation. Nine accessions including two resistant controls (Jester and Caliph) were resistant and survived PA infestation after 28 days post infestation (dpi) and went on to flower and set seed, with the exception of one individual of accession SA27063 (Table 1). The remaining 26 accessions succumbed to the PA infestation, with 15 accessions including susceptible controls (Borung and A20) with higher plant damage scores than the moderately resistant accession A17 (Table 1).

Table 1. Evaluation of 35 Medicago truncatula accessions from the South Australian Research and Development Institute (SARDI) core collection for resistance to an Australian biotype of pea aphid. Each value represents the mean and standard error (SE) of three biological replicates. For the aphid population build-up, the rating scale was as described by Gao et al. [32].

\begin{tabular}{|c|c|c|c|c|c|}
\hline Accession & $\begin{array}{l}\text { Aphid Score } \\
9 \text { dpi (SE) }\end{array}$ & $\begin{array}{l}\text { Plant Score } \\
15 \text { dpi (SE) }\end{array}$ & $\begin{array}{l}\text { Plant Score } \\
21 \text { dpi (SE) }\end{array}$ & $\begin{array}{l}\text { Plant Survivorship } \\
28 \mathrm{dpi}\end{array}$ & Comment \\
\hline SA11753 & $2.5(0.3)$ & $1.6(0.7)$ & $3.0(0.0)$ & $3 / 3$ & Resistant \\
\hline SA28645 & $2.5(0.9)$ & $2.2(0.3)$ & $3.0(0.1)$ & $3 / 3$ & Resistant \\
\hline SA3047 & $1.8(0.6)$ & $2.5(0.3)$ & $3.1(0.1)$ & $3 / 3$ & Resistant \\
\hline SA10481 & $2.8(0.4)$ & $2.3(0.3)$ & $3.3(0.2)$ & $3 / 3$ & Resistant \\
\hline SA1516 & $1.7(0.2)$ & $2.5(0.3)$ & $3.6(0.5)$ & $3 / 3$ & Resistant \\
\hline SA27192 & $1.7(0.2)$ & $1.3(0.1)$ & $3.6(0.6)$ & $3 / 3$ & Resistant \\
\hline SA27063 & $2.3(0.3)$ & $3.5(0.3)$ & $3.6(0.4)$ & $2 / 3$ & Resistant \\
\hline Caliph & $1.8(0.3)$ & $2.4(0.3)$ & $3.8(0.4)$ & $3 / 3$ & Resistant (control) \\
\hline Jester & $1.5(0.3)$ & $2.7(0.2)$ & $3.9(0.2)$ & $3 / 3$ & Resistant (control) \\
\hline SA25654 & $2.3(0.3)$ & $2.0(0.6)$ & $3.3(0.3)$ & $0 / 3$ & Moderately susceptible \\
\hline SA18395 & $1.2(0.2)$ & $2.1(0.6)$ & $3.5(0.0)$ & $0 / 3$ & Moderately susceptible \\
\hline SA8604 & $2.3(0.2)$ & $2.0(0.6)$ & $4.0(0.4)$ & $0 / 3$ & Moderately susceptible \\
\hline SA9062 & $2.3(0.3)$ & $2.3(0.3)$ & $4.0(0.4)$ & $0 / 3$ & Moderately susceptible \\
\hline SA30199 & $2.2(0.4)$ & $2.3(0.2)$ & $4.1(0.2)$ & $0 / 3$ & Moderately susceptible \\
\hline SA3569 & $2.2(0.4)$ & $2.2(0.3)$ & $4.3(0.3)$ & $0 / 3$ & Moderately susceptible \\
\hline SA10419 & $2.7(0.7)$ & $4.3(0.6)$ & $4.4(0.6)$ & $0 / 3$ & Moderately susceptible \\
\hline DZA315 & $2.8(0.6)$ & $4.0(0.1)$ & $4.6(0.1)$ & $0 / 3$ & Moderately susceptible \\
\hline SA17590 & $2.8(0.7)$ & $3.0(0.6)$ & $4.6(0.2)$ & $0 / 3$ & Moderately susceptible \\
\hline A17 & $2.7(0.2)$ & $3.0(0.5)$ & $4.7(0.1)$ & $0 / 3$ & Moderately susceptible (control) \\
\hline SA3919 & $1.7(0.4)$ & $2.3(0.6)$ & $4.7(0.2)$ & $0 / 3$ & Susceptible \\
\hline SA24968 & $2.2(0.4)$ & $3.3(0.7)$ & $4.8(0.1)$ & $0 / 3$ & Susceptible \\
\hline SA3054 & $2.8(0.4)$ & $2.9(0.9)$ & $4.8(0.1)$ & $0 / 3$ & Susceptible \\
\hline SA8618 & $3.2(0.2)$ & $3.3(0.3)$ & $4.8(0.3)$ & $0 / 3$ & Susceptible \\
\hline SA11734 & $2.5(0.3)$ & $4.1(0.5)$ & $4.9(0.1)$ & $0 / 3$ & Susceptible \\
\hline SA9357 & $3.8(0.2)$ & $4.3(0.2)$ & $4.9(0.1)$ & $0 / 3$ & Susceptible \\
\hline SA22323 & $3.3(0.3)$ & $4.3(0.3)$ & $5.0(0.0)$ & $0 / 3$ & Susceptible \\
\hline SA7749 & $3.2(0.3)$ & $4.6(0.1)$ & $5.0(0.0)$ & $0 / 3$ & Susceptible \\
\hline SA9710 & $2.5(0.3)$ & $4.5(0.3)$ & $5.0(0.0)$ & $0 / 3$ & Susceptible \\
\hline SA9712 & $2.7(0.2)$ & $4.4(0.2)$ & $5.0(0.0)$ & $0 / 3$ & Susceptible \\
\hline Cyprus & $3.0(0.6)$ & $4.5(0.3)$ & $5.0(0.0)$ & $0 / 3$ & Susceptible (control) \\
\hline Borung & $3.3(0.2)$ & $4.9(0.1)$ & $5.0(0.0)$ & $0 / 3$ & Susceptible (control) \\
\hline A20 & $3.7(0.2)$ & $4.8(0.1)$ & $5.0(0.0)$ & $0 / 3$ & Susceptible (control) \\
\hline SA1499 & $3.3(0.2)$ & $4.4(0.2)$ & $5.0(0.0)$ & $0 / 3$ & Susceptible \\
\hline DZA045 & $3.0(0.5)$ & $4.8(0.1)$ & $5.0(0.0)$ & $0 / 3$ & Susceptible \\
\hline SA1489 & $3.7(0.2)$ & $4.9(0.1)$ & $5.0(0.0)$ & $0 / 3$ & Susceptible \\
\hline
\end{tabular}


In a subsequent experiment the nine resistant accessions and five highly susceptible accessions from the initial screen were infested to confirm their resistance response to PA infestation with A17 included as a moderately resistant control. Starting with the initial two adult apterous aphids, PA colony density on all susceptible accessions peaked around $12 \mathrm{dpi}$; thereafter, the plants succumbing to PA infestation by 15 dpi. PA population density on A17 plants, the moderately resistant accession, reached the peak around $15 \mathrm{dpi}$ (Table S2), whereas aphid populations were the largest at $21 \mathrm{dpi}$ on the resistant accessions and declined thereafter at $24 \mathrm{dpi}$ (Table S2). Plant damage on resistant accessions SA1516, SA28645, SA10481, SA10733, Jester and SA11753 remained stable from 21 dpi onwards with an average score of 3.4 (Table S3).

There were some notable differences in the population sizes of PA on the different resistant accessions with a notably lower population density on SA1516 and SA10481 compared to Jester. In a follow-up short-term infestation experiment the performance of PA nymphs over a four-day period was observed, and this reflected the plant damage and aphid densities seen in the long term experiments (Figure 2). The PA nymph population had a significantly lower mean relative growth rate (MRGR) on Jester, SA10733, SA1516 and SA10481 compared to the moderately resistant A17, which, in turn, had a significantly lower MRGR compared to the highly susceptible accessions A20 and Cyprus (Figure 2a) (Tukey Kramer HSD test; $p<0.05$ ). No significant differences between the accessions were found for the survivorship of PA nymphs over this four-day period (Figure 2b) (Tukey Kramer HSD test; $p<0.05)$.

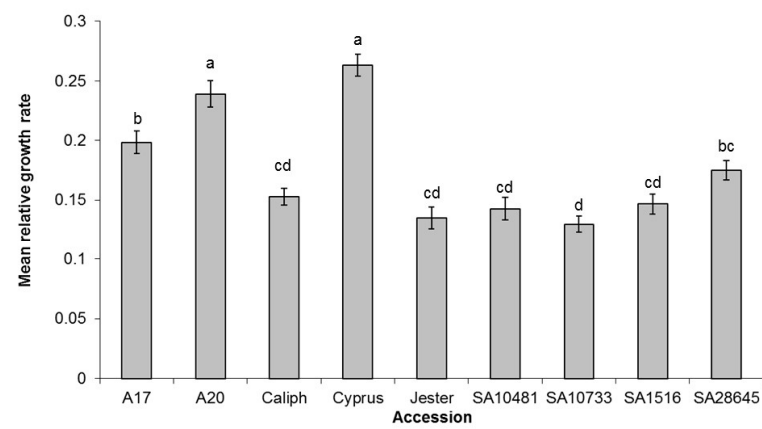

(a)

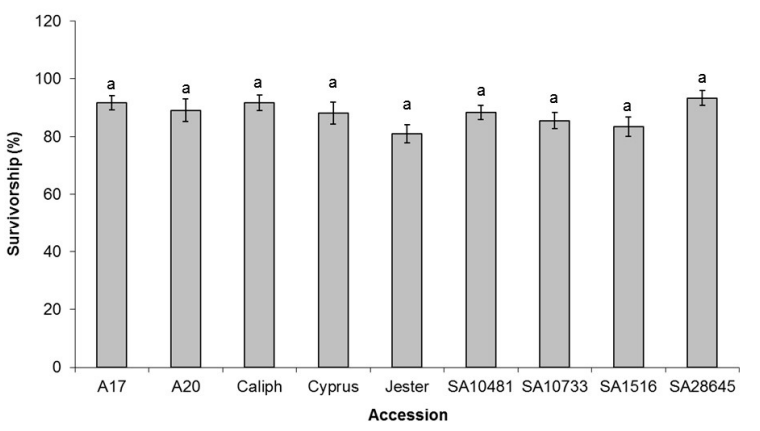

(b)

Figure 2. (a) Mean relative growth rate (MRGR) of pea aphid nymphs on nine Medicago truncatula accessions over four days. Values are mean and standard error of ten replicates. Accessions that do not share the same letters indicate significant differences in pea aphid MRGR from the other accessions by Tukey Kramer HSD test $(p<0.05)$; (b) Survivorship of pea aphid nymphs on nine M. truncatula accessions over four days. No significant differences were observed in survivorship by Tukey Kramer HSD test $(p<0.05)$.

\subsection{Resistance in M. truncatula Accessions SA10733 and SA10481 Is Controlled by Single Dominant Gene}

SA1516 and SA10481 had the lowest average plant damage scores, albeit similar resistance phenotype to Jester and SA10733, the donor of APR in cultivar Jester. Moreover, notably lower PA population densities on accessions SA1516 and SA10481 were observed in the long-term experiments. Therefore $F_{2}$ populations were generated between the resistant accessions SA10733 and SA10481 and the highly susceptible accession A20 to determine the genetic control underlying the PA resistance in these accessions. Phenotyping of 264 and $355 F_{2}$ individuals of the SA10733 $\times$ A20 and SA10481 $\times$ A20 showed a Mendelian segregation ratio of 3:1 for PA resistance in both populations (Table 2).

To determine whether the single dominant resistance in SA10481 was allelic to that of SA10733 and/or SA1516, crosses were generated and $F_{2}$ individuals for three crosses evaluated for their resistance to PA. As shown in Table 3 no susceptible individuals were identified, for any of the 535 individuals assayed, whereas the susceptible controls and moderately resistant controls behaved 
as seen in previous experiments. Thus the single dominant resistance in SA1516 and SA10481 and SA10733 are either alleles of the same gene (e.g., $A P R$ ) or genes in a tightly linked resistance gene cluster.

Table 2. Segregation of resistance to pea aphid in resistant $M$. truncatula accession crossed with accession A20. Chi-square analysis for a single dominant Mendelian inheritance of resistance of the two $\mathrm{F}_{2}$ populations indicates single dominant, Mendelian inheritance of resistance to PA in both populations.

\begin{tabular}{ccccc}
\hline \multirow{2}{*}{ Population } & \multicolumn{4}{c}{ Resistant: Susceptible } \\
\cline { 2 - 5 } & Observed & Expected & $\chi^{2}$ & $p$ \\
\hline SA10733 $\times$ A20 & $200: 64$ & $198: 66$ & 0.081 & 0.776 \\
SA10481 $\times$ A20 & $264: 91$ & $266: 89$ & 0.076 & 0.783 \\
\hline
\end{tabular}

Table 3. Pairwise allelism test between resistant $M$. truncatula accessions. Chi-square analysis for two unlinked Mendelian dominant genes indicates the resistance genes are either allelic or tightly linked.

\begin{tabular}{ccccc}
\hline \multirow{2}{*}{ Population } & \multicolumn{4}{c}{ Resistant: Susceptible } \\
\cline { 2 - 5 } & Observed & Expected & $\chi^{2}$ & $\boldsymbol{p}$ \\
\hline SA10733 $\times$ SA1516 & $144: 0$ & $135: 9$ & 9.6 & 0.0019 \\
SA1516 $\times$ SA10481 & $100: 0$ & $93.75: 6.25$ & 6.667 & 0.010 \\
SA10481 $\times$ SA10733 & $250: 0$ & $234.4: 15.6$ & 16.667 & 0.00005 \\
\hline
\end{tabular}

\section{Discussion}

Previously, we have characterised PA resistance in the M. truncatula cultivar Jester, which also harbours resistance to bluegreen aphid [24]. The biology of the resistance to both aphid species in this cultivar shared similarities with resistances occurring at the phloem level and requires an intact plant and involves a combination of antibiosis, antixenosis and plant tolerance [14,24]. However, the donor for bluegreen aphid resistance (accession SA1499) was a different donor than that of PA resistance (accession SA10733), thus resistance to both aphids are controlled by distinct single dominant resistance genes with the PA resistance locus tentatively named APR [19]. Here we demonstrated that resistance to PA mapped $39 \mathrm{cM}$ distal of the flanking markers for the bluegreen aphid resistance locus AKR (h2_6g9b and 004H01) on chromosome 3 in a region rich in classical NLR type of resistance gene (Figure 1). Moreover, the region that contains $A P R$ in the genetic background of Jester spans the same region as the region harbouring RAP1 to the European PA biotype LS01 in the genetic background of A17 [17]. This could mean that $A P R$ and RAP1 are either two different alleles of the same orthologous gene, or, alternatively, two different genes in a NLR cluster of resistance genes. Further fine-mapping will be achieved in future work by generating re-sequencing data for cultivar Jester to identify single nucleotide polymorphisms (SNPs) or insertions/deletions (indels) in the APR region with the 26 recombinant $\mathrm{F}_{3}$ families. This would narrow-down the region of interest further and allow a map-based cloning approach for the APR locus. Similarly, the use of the Medicago HapMap resources [33] that contains re-sequencing data for DZA315 would allow the identification of SNPs and indels to generate novel markers for further fine-mapping of the RAP1 locus.

Screening of diverse M. truncatula accessions with eight different European biotypes has previously been conducted by Kanvil and colleagues [27] and showed a range of differences in performance of the different biotypes across $23 \mathrm{M}$. truncatula accessions. They demonstrated that aphid virulence and host resistance were strongly dependent on the genotype of both the aphid and the host where diverse host-specific PA performance and biotype specific resistance in M. truncatula were observed. In Australia, there is currently only one biotype present and in contrast to the study by Kanvil et al. [27], no lethal resistance to the Australian biotype was identified in M. truncatula germplasm. Despite this result, seven new accessions were identified as being resistant to PA at a similar level to SA10733 and Jester both harbouring the APR gene, with notably lower PA population 
densities on accessions SA1516 and SA10481 compared to current cultivar Jester (Figure 2, Table 1). To determine the genetic control of PA resistance in the resistant accessions, crosses were generated to the susceptible $\mathrm{A} 20$ and phenotyping of the $\mathrm{F}_{2}$ populations showed that resistance segregated in a Mendelian fashion for a single dominant gene (Table 2), raising the question whether the resistance identified in these accessions were allelic to $A P R$, a gene somewhat linked to $A P R$ or an unlinked gene. Out of the $494 \mathrm{~F}_{2}$ individuals phenotyped none of them showed susceptibility, which suggests that the single dominant resistance in SA1516, SA10481 and SA10733 are either alleles of the same gene (e.g., $A P R$ ) or genes in a tightly linked resistance gene cluster. The latter could be a valid hypothesis as the RAP1 gene is also located in the same region on chromosome 3 , and this region contains a suite of NLR resistance genes. The RAP1 gene in M. truncatula provides race-specific resistance to pea aphid biotype PS01 but not to biotype LL01 [17]. Furthermore, it has been shown that different PA biotypes (both sexual and asexual clones) differ in their performance on a range of $M$. truncatula accessions, including Jester and A17 plants [27]. Another PA biotype, N116, was virulent on RAP1 genotypes like biotype LL01 as well as on a wide range of other cultivars and wild $M$. truncatula genotypes [27]. On the contrary, PS01 was avirulent on most of the M. truncatula accessions. The divergent performance of these PA biotypes allowed the determination of inheritance of aphid virulence, and it was demonstrated through a series of $\mathrm{F}_{1}$ progenies of clones N116 and PS01 that the RAP1 mediated resistance can be overcome by progeny from either selfing or reciprocal crosses [34]. This suggest that the annual sexual cycle in aphids can lead to the generation of novel genotypes, which might have increased or decreased virulence. In turn, $M$. truncatula has to adapt and develop new forms of resistance to PA. In other plant species, this adaptation to other forms of virulent pathogens/pests occurs according to the birth and death model of $R$ genes where $R$-genes duplicate and diversify in gene clusters [35]. Further fine-mapping of the identified PA resistance loci would shed more light on whether this has occurred in M. truncatula in response to different PA biotypes.

The identification of the APR resistance gene in M. truncatula cv. Jester is the fourth major aphid resistance gene in this genetic background (Figure 3), which also harbours resistance to bluegreen aphid conferred by genes $A K R$ [14] and AIN [16] and spotted alfalfa aphid conferred by TTR [15]. Breeders introgressed resistance to bluegreen aphid and spotted alfalfa aphid into the genetic background of Jemalong A17 from various resistance sources [19,23]. Since the APR locus is located $10.5 \mathrm{cM}$ distal of the flanking marker for TTR in the Jester $\mathrm{xA} 20$ population and thus somewhat linked to TTR, they coincidentally introduced resistance to PA as well (Figure 3). The wealth of $M$. truncatula genomic resources including a reference genome sequence for Jemalong A17 [36,37] and a genome sequence for the model aphid PA [25] makes the M. truncatula-PA system a great one to study plant-insect interactions and $R$ gene specificity and evolution. Similarly, PA genomic datasets such as numerous Expressed Sequence Tags (EST) and transcriptome resources [38] and RNA interference methods to silence aphid genes $[39,40]$ would complement the plant based studies and allow the identification of aphid effectors recognised by the resistance genes. The use of these resources and in addition to the advances in sequencing technologies and Clustered regularly interspaced short palindromic repeats (CRISPR)/Cas9 should allow the development of new ways to identify essential PA genes to establish a feeding site and/or effectors recognized by the resistance locus and might lead to effective durable resistance to aphids. 


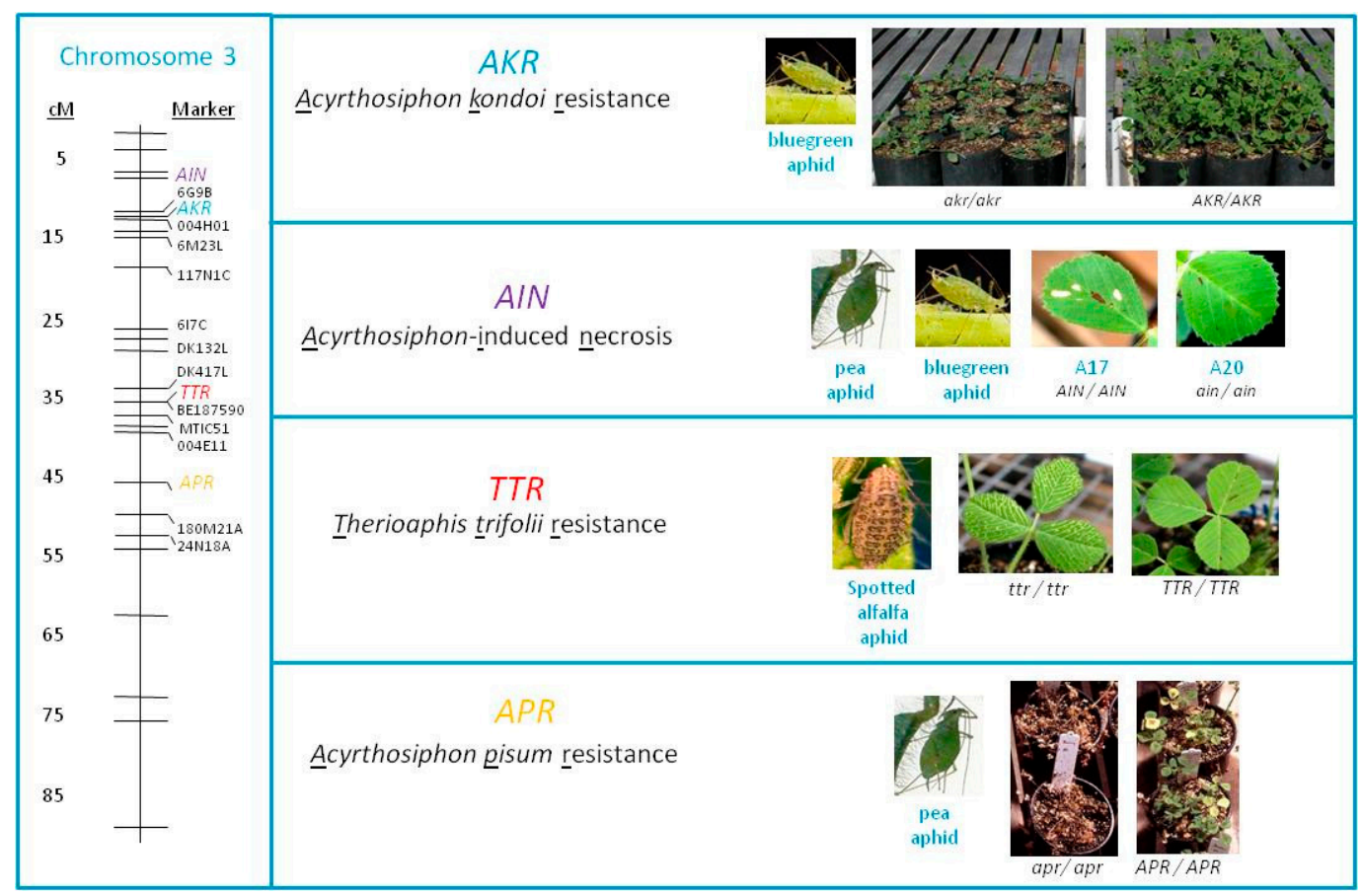

Figure 3. Overview of the major resistance genes identified in M. truncatula cv. Jester to three different aphid species.

\section{Materials and Methods}

\subsection{Plants and Aphids}

Three genotypes of M. truncatula were mainly used being: Jester, A17 and A20. Genetic $\mathrm{F}_{2 ; 3}$ mapping populations derived from crosses derived between both Jester and A20, and Jester and A17, were generated using a crossing procedure described by Thoquet et al [41] and used in this study for the genetic mapping and phenotyping for PA resistance. The M. truncatula core collection accessions were acquired from the South Australian Research and Development Institute (SARDI, Urrbrae, Australia). Accessions DZA315 and DZA045 were obtained from the Institut National de la Recherche Agronomique (INRA), Montpellier, France. Seeds were germinated and plants grown as described by Klingler et al. [16]. The aphid species used was PA collected in Western Australia and were reared on faba bean (Vicia faba), as described by Gao et al. [32].

\subsection{Plant Damage and PA Performance Tests}

To assess the performance of PA and plant feeding damage, two-week-old seedlings of $M$. truncatula lines A17, A20 and Jester as well as $129 \mathrm{~F}_{3}$ families ( $n=12$ per $\mathrm{F}_{3}$ family) of the Jester $\times \mathrm{A} 20$ population and $26 \mathrm{~F}_{3}$ families ( $n=12$ per $\mathrm{F}_{3}$ family) of the Jester $\times$ A17 population were grown in separate $0.9 \mathrm{~L}$ pots and were infested with two apterous adult aphids. Similarly, the 35 accessions (Table 1) were screened for PA resistance in a glasshouse when two-week-old and infested with two apterous adult aphids. The screening of the 35 accessions was arranged in a randomized complete block design with three replicates per accession infested for 28 days.

In all phenotyping experiments the aphids were allowed to develop, reproduce, and move freely among plants. Aphid population build-up and feeding damage on plants were assessed at a three-day interval from the third day up to 28 days post infestation using a scale from $1-5$ and $0-5$, respectively as described previously [20]. 


\subsection{Aphid Performance on Caged Leaves}

The survival and growth rate of PA were measured after four days on individual plants of each $M$. truncatula accession with ten replicates for each accession and the mean relative growth rate (MRGR) calculated as described by Gao et al. [32]. The proportion of aphids that survived and MRGR were compared using the Tukey-Kramer Honestly Significant Difference test with the JMP-IN 5.1 software (SAS Institute, Cary, NC, USA).

\subsection{Genetic Mapping of PA Resistance in the Various Mapping Populations}

Genetic maps for the Jester $\times$ A20 and Jester $\times$ A17 mapping populations were generated using both microsatellite and gene-based markers generated by the Medicago research community. Previously we established linkage association with markers on linkage group 3 [24] and therefore markers were initially selected to be evenly distributed over linkage group 3 and were obtained from several published sources [28-30]. A total of 26 markers were characterised for the Jester $\times$ A20 $(n=129)$ and for Jester $\times$ A17 $(n=384)$ populations with the polymorphic markers for the respective populations listed in Table S1.

Linkage group 3 was constructed for both mapping populations using a set of 15 and 8 markers for the Jester $\times$ A20 and the Jester $\times$ A17 population respectively, using Multipoint v1.2 (Institute of Evolution, Haifa University, Haifa, Israel) as described by Kamphuis et al. [42].

\subsection{Allelism Tests}

Pairwise crosses were made among SA10733, SA1516 and SA10481 to test the allelic status of the PA resistance in SA1516 and SA10481 as in Table 3. The seedlings of $F_{2}$ from each cross with at least eight replicates of their respective parental genotypes and A20 were tested for PA resistance. Each three-to-four-week-old seedling was infested with two apterous adult PAs for 28 days. During this period, aphids were allowed to develop, reproduce and move freely. Aphid resistance were scored as either resistant or susceptible at $28 \mathrm{dpi}$. Susceptible plants die before $20 \mathrm{dpi}$ and with overwhelming aphids around $12 \mathrm{dpi}$ and then totally migrate to the other plants due to the death of the host plant; resistant plants are still surviving at $28 \mathrm{dpi}$ and reasonably healthy. The appearance of parental lines and A20 was used as controls.

Supplementary Materials: Supplementary materials can be found at http://www.mdpi.com/1422-0067/17/ $8 / 1224 / \mathrm{s} 1$.

Acknowledgments: We would like to thank Elaine Smith and Jenny Reidy-Croft for technical assistance on the project. We would like to thank Jonathan Anderson, Andrew James and Silke Jacques for providing helpful comments on the manuscript. Su-Min Guo was supported by a CSIRO/China Scholarship Council fellowship.

Author Contributions: Lars G. Kamphuis, Ling-Ling Gao and Karam B. Singh conceived and designed the experiments; Lars G. Kamphuis and Su-Min Guo performed the experiments; Lars G. Kamphuis and Su-Min Guo analyzed the data; Lars G. Kamphuis and Karam B. Singh wrote the paper.

Conflicts of Interest: The authors declare no conflict of interest.

\section{References}

1. Ng, J.C.K.; Perry, K.L. Transmission of plant viruses by aphid vectors. Mol. Plant Pathol. 2004, 5, 505-511. [CrossRef] [PubMed]

2. Walling, L.L. Avoiding effective defenses: Strategies employed by phloem-feeding insects. Plant Physiol. 2008, 146, 859-866. [CrossRef] [PubMed]

3. Will, T.; Furch, A.C.; Zimmermann, M.R. How phloem-feeding insects face the challenge of phloem-located defenses. Front. Plant Sci. 2013, 4, 336. [CrossRef] [PubMed]

4. Kaloshian, I. Gene-for-gene disease resistance: Bridging insect pest and pathogen defense. J. Chem. Ecol. 2004, 30, 2419-2438. [CrossRef] [PubMed]

5. Kamphuis, L.G.; Zulak, K.; Gao, L.-L.; Anderson, J.P.; Singh, K.B. Plant-aphid interactions with a focus on legumes. Funct. Plant Biol. 2013, 40, 1271-1284. [CrossRef] 
6. Dangl, J.L.; Horvath, D.M.; Staskawicz, B.J. Pivoting the plant immune system from dissection to deployment. Science 2013, 341, 746-751. [CrossRef] [PubMed]

7. Jones, J.D.G.; Dangl, J.L. The plant immune system. Nature 2006, 444, 323-329. [CrossRef] [PubMed]

8. Eitas, T.K.; Dangl, J.L. NB-LRR proteins: Pairs, pieces, perception, partners and pathways. Curr. Opin. Plant Biol. 2010, 13, 472-477. [CrossRef] [PubMed]

9. Casteel, C.L.; Walling, L.L.; Paine, T.D. Behavior and biology of the tomato psyllid, Bactericerca cockerelli, in response to the Mi-1.2 gene. Entomol. Exp. Appl. 2006, 121, 67-72. [CrossRef]

10. Nombela, G.; Williamson, V.M.; Muñiz, M. The root-knot nematode resistance gene Mi-1.2 of tomato is responsible for resistance against the whitefly Bemisia tabaci. Mol. Plant Microbe Interact. 2003, 16, 645-649. [CrossRef] [PubMed]

11. Rossi, M.; Goggin, F.; Milligan, S.B.; Kaloshian, I.; Ullman, D.E.; Williamson, V.M. The nematode resistance gene $\mathrm{Mi}$ of tomato confers resistance against the potato aphid. Proc. Natl. Acad. Sci. USA 1998, 95, 9750-9754. [CrossRef] [PubMed]

12. Dogimont, C.; Chovelon, V.; Pauquet, J.; Boualem, A.; Bendahmane, A. The Vat locus encodes for a CC-NBS-LRR protein that confers resistance to Aphis gossypii infestation and A. gossypii-mediated virus resistance. Plant J. 2014, 80, 993-1004. [CrossRef] [PubMed]

13. Wroblewski, T.; Piskurewicz, U.; Tomczak, A.; Ochoa, O.; Michelmore, R.W. Silencing of the major family of NBS-LRR encoding genes in lettuce results in the loss of multiple resistance specificities. Plant J. 2007, 51, 803-818. [CrossRef] [PubMed]

14. Klingler, J.; Creasy, R.; Gao, L.; Nair, R.M.; Calix, A.S.; Spafford Jacob, H.; Edwards, O.R.; Singh, K.B. Aphid resistance in Medicago truncatula involves antixenosis and phloem-specific, inducible antibiosis, and maps to a single locus flanked by NBS-LRR resistance gene analogs. Plant Physiol. 2005, 137, 1445-1455. [CrossRef] [PubMed]

15. Klingler, J.P.; Edwards, O.R.; Singh, K.B. Independent action and contrasting phenotypes of resistance genes against spotted alfalfa aphid and bluegreen aphid in Medicago truncatula. New Phytol. 2007, 173, 630-640. [CrossRef] [PubMed]

16. Klingler, J.P.; Nair, R.M.; Edwards, O.R.; Singh, K.B. A single gene, AIN, in Medicago truncatula mediates a hypersensitive response to both bluegreen aphid and pea aphid, but confers resistance only to bluegreen aphid. J. Exp. Bot. 2009, 60, 4115-4127. [CrossRef] [PubMed]

17. Stewart, S.A.; Hodge, S.; Ismail, N.; Mansfield, J.W.; Feys, B.J.; Prosperi, J.M.; Huguet, T.; Ben, C.; Gentzbittel, L.; Powell, G. The RAP1 gene confers effective, race-specific resistance to the pea aphid in Medicago truncatula independent of the hypersensitive reaction. Mol. Plant Microbe Interact. 2009, 22, 1645-1655. [CrossRef] [PubMed]

18. Edwards, O.R.; Singh, K.B. Resistance to insect pests, what do legumes have to offer? Euphytica 2006, 147, 273-285. [CrossRef]

19. Guo, S.; Kamphuis, L.G.; Gao, L.-L.; Edwards, O.R.; Singh, K.B. Two independent resistance genes in the Medicago truncatula cultivar Jester confer resistance to two different aphid species of the genus Acyrthosiphon. Plant Signal. Behav. 2009, 4, 1-4. [CrossRef]

20. Guo, S.; Kamphuis, L.G.; Gao, L.-L.; Klingler, J.P.; Lichtenzveig, J.; Edwards, O.R.; Singh, K.B. Identification of distinct quantitative trait loci associated with defense against the closely related aphids Acyrthosiphon pisum and A. kondoi in Medicago truncatula. J. Exp. Bot. 2012, 63, 3913-3922. [CrossRef] [PubMed]

21. Kamphuis, L.G.; Gao, L.-L.; Singh, K.B. Identification and characterization of resistance to cowpea aphid (Aphis craccivora Koch) in Medicago truncatula. BMC Plant Biol. 2012, 12, 101. [CrossRef] [PubMed]

22. Kamphuis, L.G.; Lichtenzveig, J.; Peng, K.; Guo, S.; Klingler, J.P.; Siddique, K.; Gao, L.L.; Singh, K.B. Physiology and genetics of resistance to spotted alfalfa aphid (Therioaphis trifolii) in Medicago truncatula. J. Exp. Bot. 2013, 64, 5157-5172. [CrossRef] [PubMed]

23. Hill, J.R. Jester. Plant Var. J. 2000, 13, 40.

24. Gao, L.L.; Klingler, J.P.; Anderson, J.P.; Edwards, O.R.; Singh, K.B. Characterization of pea aphid resistance in Medicago truncatula. Plant Physiol. 2008, 146, 996-1009. [CrossRef] [PubMed]

25. IAGC. Genome sequence of the pea aphid Acyrthosiphon pisum. PLoS Biol. 2010, 8, e1000313. [CrossRef]

26. Legeai, F.; Shigenobu, S.; Gauthier, J.P.; Colbourne, J.; Rispe, C.; Collin, O.; Richards, S.; Wilson, A.C.; Murphy, T.; Tagu, D. AphidBase: A centralized bioinformatic resource for annotation of the pea aphid genome. Insect Mol. Biol. 2010, 2, 5-12. [CrossRef] [PubMed] 
27. Kanvil, S.; Powell, G.; Turnbull, C. Pea aphid biotype performance on diverse Medicago host genotypes indicates highly specific virulence and resistance functions. Bull. Entomol. Res. 2014, 104, 689-701. [CrossRef] [PubMed]

28. Choi, H.K.; Kim, D.; Uhm, T.; Limpens, E.; Lim, H.; Mun, J.H.; Kalo, P.; Penmetsa, R.V.; Seres, A.; Kulikova, O.; et al. A sequence-based genetic map of Medicago truncatula and comparison of marker colinearity with M. sativa. Genetics 2004, 166, 1463-1502. [CrossRef] [PubMed]

29. Gutierrez, M.V.; Vaz Patto, M.C.; Huguet, T.; Cubero, J.I.; Moreno, M.T.; Torres, A.M. Cross-species amplification of Medicago truncatula microsatellites across three major pulse crops. Theor. Appl. Genet. 2005, 110, 1210-1217. [CrossRef] [PubMed]

30. Mun, J.H.; Kim, D.J.; Choi, H.K.; Gish, J.; Debellé, F.; Mudge, J.; Denny, R.; Endré, S.; Saurat, O.; Dudez, A.M.; et al. Distribution of microsatellites in the genome of Medicago truncatula: A resource of genetic markers that integrate genetic and physical maps. Genetics 2006, 172, 2541-2555. [CrossRef] [PubMed]

31. Ellwood, S.R.; D'Souza, N.K.; Kamphuis, L.G.; Burgess, T.I.; Nair, R.M.; Oliver, R.P. SSR analysis of the Medicago truncatula SARDI core collection reveals substantial diversity and unusual genotype dispersal throughout the Mediterranean basin. Theor. Appl. Genet. 2006, 112, 977-983. [CrossRef] [PubMed]

32. Gao, L.L.; Horbury, R.; Nair, R.M.; Edwards, O.R.; Singh, K.B. Characterization of resistance to multiple aphid species (Hemiptera: Aphididae) in Medicago truncatula. Bull. Entomol. Res. 2007, 97, 41-48. [CrossRef] [PubMed]

33. Kang, Y.; Sakiroglu, M.; Krom, N.; Stanton-Geddes, J.; Wang, M.; Lee, Y.C.; Young, N.D.; Udvardi, M. Genome-wide association of drought-related and biomass traits with HapMap SNPs in Medicago truncatula. Plant Cell Environ. 2015, 38, 1997-2011. [CrossRef] [PubMed]

34. Kanvil, S.; Collins, C.M.; Powell, G.; Turnbull, C.G.N. Cryptic virulence and avirulence alleles revealed by controlled sexual recombination in pea aphids. Genetics 2015, 199, 581-593. [CrossRef] [PubMed]

35. Michelmore, R.W.; Meyers, B.C. Clusters of resistance genes in plants evolve by divergent selection and a birth-and-death process. Genome Res. 1998, 8, 1113-1130. [PubMed]

36. Tang, H.; Krishnakumar, V.; Bidwell, S.; Rosen, B.; Chan, A.; Zhou, S.; Gentzbittel, L.; Childs, K.L.; Yandell, M.; Gundlach, H.; et al. An improved genome release (version Mt4.0) for the model legume Medicago truncatula. BMC Genom. 2014, 15, 312. [CrossRef] [PubMed]

37. Young, N.D.; Debellé, F.; Oldroyd, G.E.; Geurts, R.; Cannon, S.B.; Udvardi, M.K.; Benedito, V.A.; Mayer, K.F.; Gouzy, J.; Schoof, H.; et al. The Medicago genome provides insight into the evolution of rhizobial symbioses. Nature 2011, 480, 520-524. [CrossRef] [PubMed]

38. Gerardo, N.M.; Altincicek, B.; Anselme, C.; Atamian, H.; Barribeau, S.M.; de Vos, M.; Duncan, E.I.; Evans, J.D.; Gabaldon, T.; Ghanim, M.; et al. Immunity and other defenses in pea aphids, acyrthosiphon pisum. Genome Biol. 2010, 11, R21. [CrossRef] [PubMed]

39. Mutti, N.S.; Louis, J.; Pappan, L.K.; Pappan, K.; Begum, K.; Chen, M.-S.; Park, Y.; Dittmer, N.; Marshall, J.; Reese, J.C.; et al. A protein from the salivary glands of the pea aphid, acyrthosiphon pisum, is essential in feeding on a host plant. Proc. Natl. Acad. Sci. USA 2008, 105, 9965-9969. [CrossRef] [PubMed]

40. Mutti, N.S.; Park, Y.; Reese, J.C.; Reeck, G.R. RNAi knockdown of a salivary transcript leading to lethality in the pea aphid Acyrthosiphon pisum. J. Insect Sci. 2006, 6, 38. [CrossRef] [PubMed]

41. Thoquet, P.; Ghérardi, M.; Journet, E.; Kereszt, A.; Ané, J.; Prosperi, J.M.; Huguet, T. The molecular genetic linkage map of the model legume Medicago truncatula: An essential tool for comparative legume genomics and the isolation of agronomically important genes. BMC Plant Biol. 2002, 2, 1. [CrossRef] [PubMed]

42. Kamphuis, L.G.; Lichtenzveig, J.; Oliver, R.P.; Ellwood, S.R. Two alternative recessive quantitative trait loci influence resistance to spring black stem and leaf spot in Medicago truncatula. BMC Plant Biol. 2008, 8, 1. [CrossRef] [PubMed]

(C) 2016 by the authors; licensee MDPI, Basel, Switzerland. This article is an open access article distributed under the terms and conditions of the Creative Commons Attribution (CC-BY) license (http://creativecommons.org/licenses/by/4.0/). 